\title{
Pancreatic ascites managed with a conservative approach: a case report
}

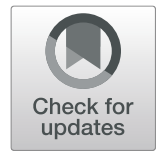

\author{
Raju Bhandari ${ }^{*}$ (D), Rajan Chamlagain ${ }^{2}$, Saraswati Bhattarai ${ }^{2}$, Eric H. Tischler $^{3}$, Rajesh Mandal ${ }^{1}$ and \\ Ramesh Singh Bhandari
}

\begin{abstract}
Background: Pancreatic ascites refers to the massive accumulation of pancreatic fluid in the peritoneal cavity and is a rare entity. Chronic alcoholic pancreatitis is the most common cause. Ascites is commonly seen in patients with alcoholic liver disease and is usually a consequence of portal hypertension. Biliary pancreatitis, pancreatic trauma and cystic duplications of biliopancreatic ducts, ampullary stenosis, or ductal lithiasis are the remaining causes.

Case presentation: A 53-year-old Chhetri man, a chronic alcoholic, presented with epigastric pain and abdominal distension. He had made several previous visits to a local hospital within the past 6 months for a similar presentation. Serum alkaline phosphatase $248 \mathrm{IU} / \mathrm{L}$, serum amylase $1301 \mathrm{IU} / \mathrm{L}$, and lipase $1311 \mathrm{IU} / \mathrm{L}$ were elevated while serum calcium was decreased $(1.5 \mathrm{mmol} / \mathrm{l})$. Ascitic fluid amylase was elevated (2801 IU/L). A computed tomography scan of his abdomen revealed features suggestive of acute-on-chronic pancreatitis. The case was managed with a conservative approach withholding oral feedings, starting total parenteral nutrition, paracentesis, octreotide, and pigtail drainage.

Conclusion: Pancreatic ascites is a rare entity. Diagnosis is suspected with raised ascitic fluid amylase in the presence of pancreatic disease. Such cases can be managed by conservative approach or interventional approach. We managed this case through a conservative approach.
\end{abstract}

Keywords: Pancreatitis, Ascites, Surgical, Medical, Case report

\section{Background}

Massive ascites in a chronic alcoholic patient is usually attributed to hepatic cirrhosis [1]. Pancreatic ascites should be suspected in patients with chronic alcoholism and pancreatitis presenting with ascites [2]. The etiology is probably a pancreatic pseudocyst leakage or ductal disruption [3]. The diagnosis is based on demonstration of ascitic fluid amylase (>1000 U/L). Chronic pancreatitis $(83 \%)$, acute pancreatitis (8.6\%), and trauma (3.6\%) are common causes for ductal disruption. Medical treatment includes withholding oral feedings, total parenteral nutrition (TPN), paracentesis, and administering octreotide [4]. For those not responding to medical therapy,

\footnotetext{
* Correspondence: rbiom27@gmail.com

${ }^{1}$ Department of General and Gl Surgery, Tribhuvan University Teaching Hospital, Kathmandu, Nepal

Full list of author information is available at the end of the article
}

interventional therapy may be needed which includes endoscopic transpapillary pancreatic duct stenting or surgery which includes cystogastrostomy, cystenterostomy, pancreatic sphincterectomy, or partial pancreatic resection [5-7]. We present a case of massive ascites in a patient with chronic pancreatitis secondary to chronic alcohol use. The case was successfully managed with a combination of medical and interventional therapy.

\section{Case presentation}

A 53-year-old, Chhetri man with a history of 10-12 years of chronic alcoholism presented to our hospital with the chief complaints of weight loss of $18 \mathrm{~kg}$ over the past 6 months, as well as epigastric pain and vomiting for the past month. Otherwise, there was no documented history of fever, yellowish discoloration of skin, gastrointestinal bleeding, melena, dark-colored urine or

\section{$\triangle B M C$}

(c) The Author(s). 2020 Open Access This article is licensed under a Creative Commons Attribution 4.0 International License, which permits use, sharing, adaptation, distribution and reproduction in any medium or format, as long as you give appropriate credit to the original author(s) and the source, provide a link to the Creative Commons licence, and indicate if changes were made. The images or other third party material in this article are included in the article's Creative Commons licence, unless indicated otherwise in a credit line to the material. If material is not included in the article's Creative Commons licence and your intended use is not permitted by statutory regulation or exceeds the permitted use, you will need to obtain permission directly from the copyright holder. To view a copy of this licence, visit http://creativecommons.org/licenses/by/4.0/ The Creative Commons Public Domain Dedication waiver (http://creativecommons.org/publicdomain/zero/1.0/) applies to the data made available in this article, unless otherwise stated in a credit line to the data. 
pale stool. His past medical or surgical history was not significant. He had been admitted to a local hospital on several occasions in the past 6 months with similar complaints and was diagnosed as having acute mild pancreatitis, which was managed conservatively. His current pain was moderate to severe in intensity, radiating to his back, and it was aggravated by meals and relieved on stooping forward. $\mathrm{He}$ had associated symptoms of non-projectile, non-bloody, and nonbilious vomiting, only containing water and food contents. Furthermore, he also complained of respiratory discomfort that was concurrent with pain episodes. On examination, he was ill appearing and had the following vital signs: pulse of 124 beats per minute, temperature $37^{\circ} \mathrm{C}\left(98.6^{\circ} \mathrm{F}\right)$, and blood pressure of $110 / 70 \mathrm{~mm} \mathrm{Hg}$. An abdominal examination revealed marked generalized abdominal tenderness. Bowel sounds were normal. Other systemic examinations were not significant.

With regards to laboratory values, total cell and differential counts, electrolytes, bilirubin, serum glutamicoxaloacetic transaminase (SGOT)/serum glutamic-pyruvic transaminase (SGPT), lactate dehydrogenase (LDH), serum protein, serum albumin, and urine and stool analysis were within normal limits at the time of admission. However, serum alkaline phosphatase (ALP; $248 \mathrm{IU} / \mathrm{L}$ ), amylase (1301 IU/L), and lipase (1311 IU/L) were elevated while serum calcium was decreased $(1.5 \mathrm{mmol} / \mathrm{l})$. Tumor markers CA 19-9 and carcinoembryonic antigen (CEA) were within normal limits. Arterial blood gas analysis revealed respiratory alkalosis: $\mathrm{pH}=7.48$, partial pressure of carbon dioxide $\left(\mathrm{pCO}_{2}\right) 28 \mathrm{mmHg}$, and bicarbonate $\left(\mathrm{HCO}_{3}\right) 21.3 \mathrm{mmol} / \mathrm{l}$. Ultrasonography (USG) of his abdomen and pelvis revealed features suggestive of complicated acute pancreatitis with loculated peripancreatic collection extending to the bilateral perinephric space; however, it was noted to be more prominent on the left side. He was admitted with the diagnosis of acute pancreatitis and treated conservatively. He was kept nil by mouth with the initiation of TPN, octreotide infusion, intravenous fluid (Ringer's lactate solution; RL), morphine, and paracetamol. A central venous catheter was inserted.

On the third day of admission, he developed abdominal distension with pain and maximal fever of $37.8^{\circ} \mathrm{C}$ $\left(100.1^{\circ} \mathrm{F}\right)$. USG-guided diagnostic tapping of ascitic fluid was performed. Ascitic fluid analysis revealed white blood cell count of 1740 cells $/ \mathrm{mm}^{3}$ with $60 \%$ granulocytes, total protein of $3.6 \mathrm{~g} / \mathrm{dl}$, and albumin of $1.8 \mathrm{~g} / \mathrm{dl}$. Blood culture was negative at that time. On subsequent days, leukocyte counts decreased to $13,000 / \mathrm{mm}^{3}$ from $17,000 / \mathrm{mm}^{3}$. Ascitic fluid amylase was $2801 \mathrm{IU} / \mathrm{L}$ and adenosine deaminase was $11 \mathrm{U} / \mathrm{ml}$. Serum ascites albumin gradient (SAAG), the difference in serum and ascitic fluid albumin level, was $1.0 \mathrm{~g} / \mathrm{dl}$ signifying non-portal cause. A computed tomography (CT) scan of his abdomen and pelvis revealed decreased pancreatic bulk with mildly prominent pancreatic duct and a small cystic area in the uncinate process with adjacent peripancreatic and retroperitoneal collection extending to bilateral pararenal space, which suggested acute-on-chronic pancreatitis (Fig. 1).

On the tenth day of admission, a 10F pigtail drainage was inserted in his right pelvic cavity in paracolic gutter which drained approximately $472 \mathrm{ml}$. Previously, the drainage from the same site at first day was $3000 \mathrm{ml}$ and $20 \mathrm{ml}$ on eighth day. Meanwhile, abdominal girth reduced from $78 \mathrm{~cm}$ to $68 \mathrm{~cm}$ during the same duration. He improved clinically and symptomatically and was discharged on the 22nd day of admission. On a follow-up clinic visit 1 week later, our patient was noted to have marked improvement in abdominal distension and discomfort.

\section{Discussion}

Pancreatic ascites refers to the massive accumulation of pancreatic fluid in the peritoneal cavity. The prevalence rate of pancreatic ascites is only $1 \%$; it is more common in men than in women (male:female ratio 2:1) and between 20 and 50 years of age [8]. Ascites is commonly seen in patients with alcoholic liver disease and is usually a consequence of portal hypertension. Biliary pancreatitis, pancreatic trauma and cystic duplications of biliopancreatic ducts, ampullary stenosis, or ductal lithiasis account for the remainder of cases [9]. It occurs in approximately $4 \%$ of patients with chronic pancreatitis and $6-14 \%$ of patients with pancreatic pseudocysts. It may also occur after an incidence of acute pancreatitis or blunt abdominal trauma causing duct dehiscence. The diagnosis should be considered in patients with chronic ascites with a history of alcoholism, chronic pancreatitis, or abdominal trauma [8]. In $80 \%$ of cases, pancreatic ascites results from leakage from a pseudocyst in communication with the ductal system; ductal disruption in the absence of pseudocyst accounts for the remaining $20 \%$ of cases [5].

Patients with pancreatic ascites often present with symptoms of mild abdominal pain, decreased appetite and sense of fullness, weight loss, and progressive ascites. They often present with a history of chronic pancreatitis, a recent episode of acute pancreatitis, or with new-onset ascites. However, these symptoms may be absent in alcoholics and the diagnosis may be falsely attributed to cirrhosis. Diagnosis can be made by paracentesis and analysis of the fluid for protein and amylase content. Pancreatic ascites is an exudative ascites characterized by high amylase concentration in ascitic fluid (usually over $1000 \mathrm{IU} / \mathrm{L}$ ) and protein concentration over $3 \mathrm{~g} / \mathrm{dl}$, which differentiates it from cirrhosis, tuberculosis, or carcinomatosis. Rarely, the origin is indeterminate in 


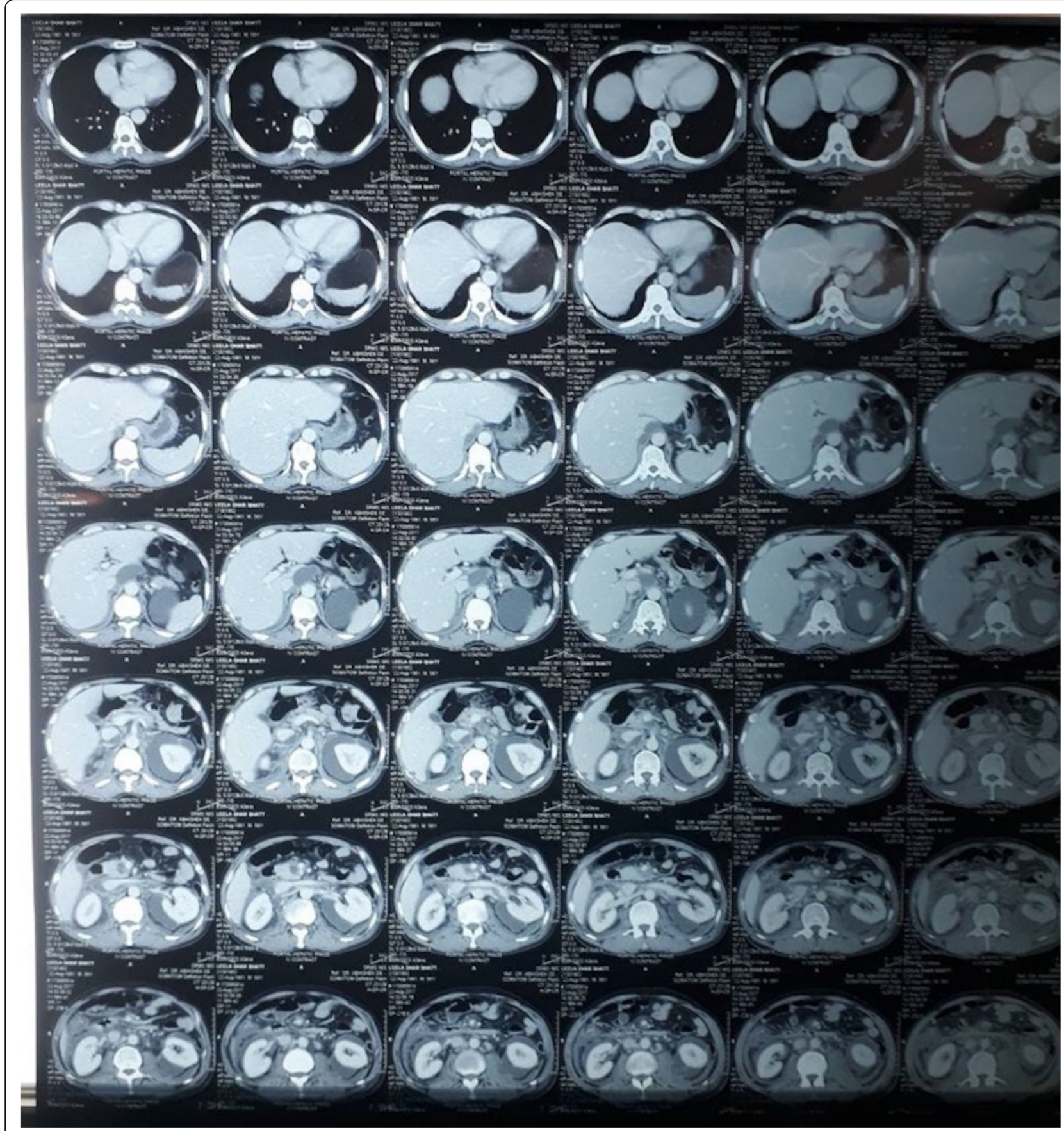

Fig. 1 Computed tomography scan of the abdomen and pelvis showing decreased pancreatic bulk and small cystic area in uncinate process with adjacent peripancreatic and retroperitoneal collection extending to bilateral pararenal space

$10 \%$ of cases. In addition to ascites, pleural effusion may be seen in such cases [10].

Once the diagnosis has been established, abdominal CT should be done to rule out pseudocysts. The use of endoscopic retrograde cholangiopancreatography (ERCP) has been suggested to help localize ductal obstruction or the site of leakage for stenting when possible. Magnetic resonance cholangiopancreatography
(MRCP) can delineate the anatomy of pancreatic duct and any abnormalities present and can be considered for candidates who cannot undergo ERCP [11]. However, the role of MRCP in the diagnosis of pancreatic ascites is not clear due to a paucity of data.

Therapy for pancreatic ascites is controversial [8]. There are no randomized control studies regarding therapy due to the rarity of the condition. A patient with 
pancreatic ascites may be managed conservatively withholding oral feedings and starting TPN. These minimize pancreatic secretions. One third of patients usually improve with this conservative approach while some may require treatment with octreotide or other somatostatin analogs, diuretics, and repeated paracentesis. Segal et al. conducted a prospective study to evaluate the efficacy of a long-acting somatostatin analogue called Sandostatin (octreotide) among 18 patients with either pancreatic ascites or external pancreatic fistulas (12). The ascites resolved in nine out of ten patients in a mean period of 22 days (+/ -3 days). The external fistulas were all highoutput fistulas and resolved in seven out of eight patients. These results indicate the value of conservative patient management [12].

The total duration of therapy is unknown and a trial of 4-6 weeks is suggested with a consideration for interventional therapy if the condition does not resolve. This approach led to healing in less than $50 \%$ of patients and overall mortality of $15 \%$ and $15-25 \%$ recurrence [9].

Fortunately, our patient improved with conservative management. Patients who fail conservative therapy require interventional therapy which can be either endoscopic or surgical. ERCP is a valuable tool in the evaluation of patients with pancreatic ascites to locate the site of disruption and, subsequently, placement of a transpapillary stent to bypass the obstruction in addition to largevolume paracentesis. In addition, patients can undergo concomitant endoscopic or percutaneous pseudocyst drainage [8].

Surgical therapy is recommended when there is no response to conservative therapy in 3-4 weeks. The choice of surgery depends on the site of leakage and associated pancreatic abnormality as demonstrated by ERCP and contrast-enhanced CT. Pseudocysts are usually treated by distal pancreatectomy when the leak is in the pancreatic tail or drained by cystogastrostomy, cystojejunostomy, or cystoduodenostomy. Studies have shown that internal pancreatic drainage is the ideal surgical treatment for patients with pancreatic ascites and/or pleural effusion that do not respond to medical treatment. When this is not feasible, external drainage can be used as an alternative to pancreatic resection [7]. Fistulas in the pancreatic duct are usually drained to a Roux-en-Y jejunal loop. Recurrence rates from 50 to $64 \%$ have been reported in patients undergoing surgical intervention without ERCP [8]. Mortality rates have been reported to be similar with surgical and medical therapies (15-25\%) [8].

We successfully managed our patient with a conservative approach. Our case highlights a few important messages. First, we often label the ascites as cirrhotic or secondary to portal hypertension given its high prevalence; it is important to also consider pancreatic ascites as part of the differential. As a clinician, it is important not to miss cases of pancreatic ascites. Past history or recent history of pancreatitis, recurrent admissions to an emergency room due to abdominal pain in chronic alcoholics, or history of blunt abdominal trauma may provide important guidance in diagnosing such cases. Furthermore, evaluation of the SAAG can be accurately measured to narrow the diagnosis. Paré et al. reported that SAAG calculation offers the best diagnostic discrimination between ascites caused by liver disease and ascites caused by a neoplasm [13]. Second, such cases are typically rare, and if diagnosed can be managed with medical and/or interventional therapy.

\section{Conclusion}

Alcoholic chronic pancreatitis is the most common cause of pancreatic ascites; it is a rare entity. Biliary pancreatitis, pancreatic trauma and cystic duplications of biliopancreatic ducts, ampullary stenosis, or ductal lithiasis account for the remainder of cases. Diagnosis is usually clinched by raised ascitic fluid amylase ( $>3$ times that of plasma), raised total ascitic protein level $(>3 \mathrm{~g} / \mathrm{dl})$ and low SAAG $(<1.1 \mathrm{~g} / \mathrm{dl})$ in the presence of pancreatic disease, and such cases can be managed by a conservative approach.

\section{Abbreviations \\ TPN: Total parenteral nutrition; CEA: Carcinoembryonic antigen; CT: Computed tomography; ERCP: Endoscopic retrograde cholangiopancreatography; MRCP: Magnetic resonance cholangiopancreatography; $\mathrm{HCO}_{3}$ : Bicarbonate; $\mathrm{LDH}$ : Lactate dehydrogenase; ALP: Alkaline phosphatase; $\mathrm{PCO}_{2}$ : Partial pressure of carbon dioxide; RL: Ringer's lactate solution; SGOT: Serum glutamic-oxaloacetic transaminase; SGPT: Serum glutamic-pyruvic transaminase; USG: Ultrasonography; \\ SAAG: Serum ascites albumin gradient}

\section{Acknowledgements}

Not applicable.

\section{Authors' contributions}

RB was involved in treating the patient, manuscript writing, and reviewing. RC was involved in manuscript writing and reviewing. SB was involved in treating the patient and manuscript reviewing. EHT was involved in reviewing the manuscript. RM and RSB were involved in treating the patient and reviewing the manuscript. The authors read and approved the final manuscript.

\section{Funding}

No funding was required for this work.

\section{Availability of data and materials}

All data are within the article.

Ethics approval and consent to participate Not applicable.

\section{Consent for publication}

Written informed consent for publication of this case report and accompanying images was obtained from the patient. A copy of the written consent is available for review by the Editor-in-Chief of this journal.

\section{Competing interests}

None of the authors have any conflict of interest to disclose. We confirm that we have read the Journal's position on issues involved in ethical publication and affirm that this case report is consistent with those guidelines. 


\section{Author details}

'Department of General and GI Surgery, Tribhuvan University Teaching Hospital, Kathmandu, Nepal. ${ }^{2}$ Tribhuvan University, Institute of Medicine, Maharajgunj, Kathmandu, Nepal. ${ }^{3}$ Department of Orthopedic Surgery and Rehabilitation Medicine, State University of New York, Downstate Medical Center, Brooklyn, New York, USA.

Received: 1 June 2020 Accepted: 27 July 2020

Published online: 15 September 2020

\section{References}

1. Martínez-Esparza M, Tristán-Manzano M, Ruiz-Alcaraz AJ, García-Peñarrubia P. Inflammatory status in human hepatic cirrhosis. World J Gastroenterol. 2015; 21(41):11522-41. Available from: https://pubmed.ncbi.nlm.nih.gov/26556984.

2. Neoptolemos JP, Winslet MC. Pancreatic Ascites. In: Beger HG, Büchler M, Ditschuneit $\mathrm{H}$, Malfertheiner P, editors. Chronic Pancreatitis. Berlin, Heidelberg: Springer Berlin Heidelberg; 1990. p. 269-79.

3. Bradley EL, Gonzalez AC, Clements JL Jr. Acute pancreatic pseudocysts: incidence and implications. Ann Surg. 1976;184(6):734-7. Available from: https://pubmed.ncbi.nIm.nih.gov/999349.

4. Nayak SK, Gaadhe RL, Piramanayagam P, Palaniswamy KR. A young man with skin rash and ascites. Trop Doct. 2015;46(1):60-1. https://doi.org/10. $1177 / 0049475515585617$

5. Bhasin DK, Malhi NS, Nagi B, Singh K. Pancreatic ascites treated by endoscopic pancreatic sphincterotomy alone: A case report. Gastrointest Endosc. 2003:57(6):802-4. https://doi.org/10.1067/mge.2003.221.

6. He W-H, Xion Z-J, Zhu Y, Xia L, Zhu Y, Liu P, et al. Percutaneous Drainage Versus Peritoneal Lavage for Pancreatic Ascites in Severe Acute Pancreatitis: A Prospective Randomized Trial. Pancreas. 2019;48(3) Available from: https://journals.Iww.com/pancreasjournal/Fulltext/2019/03000/ Percutaneous_Drainage_Versus_Peritoneal_Lavage_for.7.aspx.

7. Gupta S, Gaikwad N, Samarth A, Sawalakhe N, Sankalecha T. Efficacy of Pancreatic Endotherapy In Pancreatic Ascites And Pleural Effusion. Med Sci (Basel, Switzerland). 2017;5(2)):6. Available from: https://pubmed.ncbi.nlm. nih.gov/29099022.

8. Kanneganti K, Srikakarlapudi S, Acharya B, Sindhaghatta V, Chilimuri S. Successful Management of Pancreatic Ascites with both Conservative Management and Pancreatic Duct Stenting. Gastroenterol Res. 2009;2(4): 245-7. Available from: https://pubmed.ncbi.nlm.nih.gov/27942284.

9. Kozarek RA. Management of pancreatic ascites. Gastroenterol Hepatol (N Y). 2007;3(5):362-4. Available from: https://pubmed.ncbi.nlm.nih.gov/21960852.

10. Pai $C G$, Suvarna $D$, Bhat $G$. Endoscopic treatment as first-line therapy for pancreatic ascites and pleural effusion. J Gastroenterol Hepatol. 2009;24(7): 1198-202. https://doi.org/10.1111/j.1440-1746.2009.05796.x.

11. Soto JA, Barish MA, Yucel EK, Clarke P, Siegenberg D, Chuttani R, et al. Pancreatic duct: MR cholangiopancreatography with a three-dimensional fast spin-echo technique. Radiology. 1995;196(2):459-64. https://doi.org/10. 1148/radiology.196.2.7617861

12. Segal I, Parekh D, Lipsclütz J, Gecelter G, Myburgh Baragwanath JA, Hospitals J. Treatment of Pancreatic Ascites and External Pancreatic Fistulas with a Long-Acting Somatostatin Analogue (Sandostatin). Digestion. 1993; 54(suppl 1):53-8.

13. Paré P, Talbot J, Hoefs JC. Serum-ascites albumin concentration gradient: A physiologic approach to the differential diagnosis of ascites. Gastroenterology. 1983;85(2):240-4.

\section{Publisher's Note}

Springer Nature remains neutral with regard to jurisdictional claims in published maps and institutional affiliations.

Ready to submit your research? Choose BMC and benefit from:

- fast, convenient online submission

- thorough peer review by experienced researchers in your field

- rapid publication on acceptance

- support for research data, including large and complex data types

- gold Open Access which fosters wider collaboration and increased citations

- maximum visibility for your research: over $100 \mathrm{M}$ website views per year

At $\mathrm{BMC}$, research is always in progress.

Learn more biomedcentral.com/submissions 